\title{
Analysis of the temperature distribution in the place of fixing the ventilated facade
}

\author{
Adam Ujma* and Marta Pomada \\ Czestochowa University of Technology, Faculty of Civil Engineering, st. Akademicka 3, 42-200 \\ Czestochowa, Poland
}

\begin{abstract}
Designers more and more often choose facade systems with ventilated layers for external walls, especially in the case of new buildings. They are also used to modernize existing buildings. Mechanical connectors are a characteristic element of these constructions. Often, they are ignored in calculating the heat balance of rooms and the entire building. Because they pierce the thermal insulation layer - they cause point thermal bridges. The influence of thermal point bridges, usually made of aluminum, i.e. a material with very high thermal conductivity, for heat transfer turns out to be significant. Such thermal bridges significantly increase heat losses through building partitions. This situation increases the heat demand in the rooms to compensate for the heat loss. The article presents the results of the analysis of the impact of mechanical fasteners in ventilated facade systems on heat transfer in the building envelope. The influence of various materials and constructional solutions on the thermal conditions in these walls was investigated.
\end{abstract}

\section{Introduction}

Ventilated facade systems create favorable conditions for the exchange of heat and moisture in external walls, both in winter, at low air temperature, as in the summer, during intensive insolation of the facade.

Such constructions allow the use of a variety of materials in the thermal insulation layer, including materials with variable phase properties. There are also many material and construction proposals to finish the facade. They can be systems made of glass, metal, stone, plastic, with cementitious binder, as well as structures with installed devices that use solar radiation energy. Facade elements are mounted on a frame construction - a metal grate. The grate can be made of steel, aluminum or by joining steel with wood or aluminum with wood. The frame construction is mounted in a structural wall layer (Fig. 1) with anchors, consoles and other components. Aluminum brackets are used for mounting in the case of elevations of lighter and steel brackets in the case of heavy facades. In the place where the bracket is attached to the supporting wall structure, it is recommended to use thermal pads, also called thermostats, to limit the effect of the point thermal bridge. They can be made of PVC or other material, with a thickness in the range of 2-10 mm.

\footnotetext{
* Corresponding author: aujma55@wp.pl
} 
Elements fixing the facade go through a thermal insulation layer, usually made of mineral wool, which creates the effect of a point thermal bridge in this place. Fasteners made of aluminum, a material characterized by a very good thermal conductivity, cause the strengthening of the heat transfer process and the effect of the point thermal bridge. However, these bridges are not the only ones that are in the building envelope construction. There are also additional point bridges that are created in the place of fixing the thermal insulation to the structural layer due to the use of steel anchors (mechanical fasteners). The influence of point thermal bridges should be taken into account in the calculation of the heat transfer coefficient, because of checking the basic thermal requirements for external building envelope and the correct calculation of the energy demand for heating and the annual energy consumption of rooms or the entire building. Due to the constantly raised requirements in the field of thermal insulation of building envelope, finding structural solutions for ventilated facades that would meet new requirements is a great challenge for designers and scientists.

The basic requirements for facade systems in the European Union, including in the context of their application to the modernization of existing buildings, they were presented in [1]. Requirements for hygrothermal, acoustic and fire resistance properties have been compared and commented.

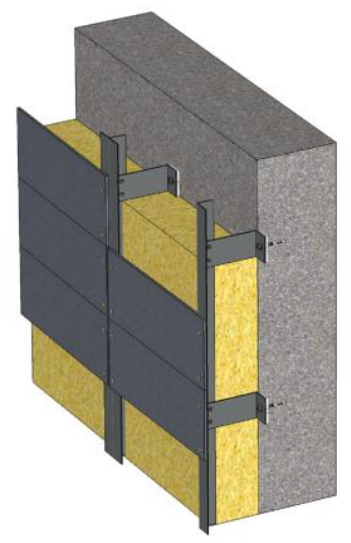

Fig. 1. Scheme of the external wall with a ventilated facade.

\section{Thermal bridges in the construction guidelines}

In the articles on facade systems, technical conditions have been defined, which should be met by individual components and the entire system as well as the rules of proper facade execution [2-4]. Consoles for grating can have a length of up to 200, $300 \mathrm{~mm}$ and more, depending on the thickness of the thermal insulation layer. This thickness is so high, due to the growing requirements in the field of thermal insulation of building envelopes. However, there are no detailed design guidelines for ventilated facades regarding important parameters to be included in the calculation of energy performance of buildings. Practically, it is not possible to obtain precise technical information about the value of point thermal bridges from fasteners and anchors passing through the thermal insulation layer, as well as the values of heat transfer coefficients for linear thermal bridges.

The ETAG 0034 guidelines [2] state that the thermal resistance $\mathrm{R}$ of a system with a ventilated facade should be calculated according to the methodology described in the standards:

- EN ISO 6946: Building components and building elements - Thermal resistance and thermal transmittance - Calculation method [5] 
- EN ISO 10211: Thermal bridges in building construction - Heat flows and surface temperatures - Detailed calculations [6]

The authors of the article [7] have tested the influence of point thermal bridges formed as a result of passing through the thermal insulation layer of anchors and consoles, to which a cladding system of a ventilated facade is mounted. The paper compares the results of the Uc coefficient calculated in accordance with the assumptions of the PN-EN ISO 6946 standard and assumptions from the work [8]. The Uc coefficient is the corrected value of the heat transfer coefficient taking into account the influence of mechanical fasteners passing through the thermal insulation layer to heat losses. For an identical structural system, the values determined according to the standard were found to be significantly larger than those determined based on assumptions from the study [8]. This confirms the conclusions from the study [9] with high inaccuracy of the $\chi$ factor value for aluminum connectors determined according to the EN ISO 6946 standard.

This situation can be important in determining the energy performance of a building, which should be of the best quality. There are often objections about the accuracy of the building's energy performance in the design documentation and the correctness of the building's energy performance certificates. The quality of results can be affected by the problem with the correct consideration of the coefficients for point and linear thermal bridges in the calculation of heat losses. One should be aware that thermal bridges are increasingly affecting the value of heating energy demand resulting from the need to heat rooms and buildings. In accordance with the approved technical construction requirements for 2021, and in the case of buildings occupied by public authorities and owned by them since 2019 , external walls with an internal temperature $t_{i}$ of $\geq 16^{\circ} \mathrm{C}$ must have a $U_{C}$ coefficient $\leq 0.20 \mathrm{~W} /\left(\mathrm{m}^{2} \cdot \mathrm{K}\right)$.

\section{Review of test results for thermal bridges}

The author of the work [10] draws attention to the very complex problem which is the effective selection of the ventilated facade construction, especially when it is to be used on an existing building. It is related to many impacts that such a construction is exposed to. The most important of them are wind loads, temperature loads including solar radiation, vibration and noise pollution from communication means, rainfall and condensation of water vapor. They cause a series of unfavorable symptoms and processes such as: displacement of elements, vibration, noise, effect of thermal and acoustic bridges and moisture. On the existing external wall of the building, this may cause additional problems due to the interaction between existing materials and the new material and construction set of the ventilated facade. That is why it is necessary to search for flexible solutions that will provide the appropriate strength parameters but at the same time protect the structure and the interior of the building from the impact of the external environment.

The process of heat transfer in place of a point thermal bridge in ventilated facade structures, assuming various material solutions, has been discussed in studies [8, 9, 11-14]. The articles $[8,12]$ show that point thermal bridges from mechanical fasteners can generate up to $25-35 \%$ of heat loss through building envelope with a ventilated facade. In order to minimize the effect of the point thermal bridge, it is necessary to use thicker thermal insulation layers [9]. This results in the need to look for solutions that could reduce these losses. There are suggestions for the use of perforated mechanical connectors with glass fiber inserts and thermal pads for fasteners [8, 11-13].

The authors of the papers $[8,12,13]$ proved that the values of the heat transfer coefficient of the thermal bridge point $\chi$ from the console together with the mounting anchor depend on the thermal conductivity value of the structural layer material. The higher the thermal conductivity value of the structural layer, the higher the value of the 
coefficient $\chi$. If the thermal conductivity changes from $0.10 \mathrm{~W} /(\mathrm{m} \cdot \mathrm{K})$ to $1.00 \mathrm{~W} /(\mathrm{m} \cdot \mathrm{K})$, an increase by several hundred percent can be observed. However, the higher value of the thermal conductivity of the thermal insulation layer and the change in the thickness of this layer, cause a decrease in the value of the coefficient $\chi$, which is a small decrease. The decisive influence on the value of this coefficient has a thermal bridge generated by the anchor fixing the console of the facade system. This anchor is made of steel, a material with good thermal conductivity of approx. $50 \mathrm{~W} /(\mathrm{m} \cdot \mathrm{K})$ for plain steel and $15-17 \mathrm{~W} /(\mathrm{m} \cdot \mathrm{K})$ for stainless steel. However, in the case of the console mounting the facade system, although it is usually made of aluminum (a material with better thermal conductivity than steel), the thermal bridge effect is practically stabilized due to its location in the thermal insulation layer.

The complexity of the point thermal bridge cannot be precisely taken into account when the values of thermal bridges from mechanical connectors are calculated only in accordance with EN ISO 6946. This standard takes into account the existence of a thermal bridge only for the console passing through the thermal insulation layer. However, the analysis of literature and research shows that the process of heat flow in this place is more complicated. Therefore, it is necessary to take into account the thermal bridge caused by the entire fixing set, i.e. the console with the fixing anchor and possibly other components.

An important aspect of facade systems research is their behavior in changing climatic conditions and in diurnal and cyclical environmental interactions. This problem is presented in paper [14], in which the conditions of air flow in the ventilated space, depending on the air temperature, solar radiation intensity, wind force and direction were analyzed. A special calculation model useful for the calculations of this type of structure has been developed.

Another important problem that can occur in the case of ventilated facades is the possibility of moisture, including moisture coming from condensation of water vapor. In the case of moisture which may appear as technological moisture from the construction period or during periods of low outside air temperature $[15,16]$, it should be taken into account as a factor strengthening the effect of the point thermal bridge. If the process of moisture accumulation and its impact on the materials of the construction layer or thermal insulation layer is not stopped, it may lead to destruction of the structure and loss of basic thermal insulation properties.

Despite proper thermal insulation, external partitions with ventilated facades should also be characterized by proper acoustic insulation and the ability to protect against vibrations that arise as a result of wind, noise and transport means [17]. These properties are influenced by the used materials and the interconnections between the elements of the facade system, including the anchoring method and the type of material in which the system is installed. The material of the structural layer with proper strength and insulation properties minimizes the effect of the acoustic bridge [18]. Also, the thermal pad under the mounting anchor, in addition to reducing the point thermal bridge, limits the effect of the sound bridge.

The point thermal bridges have a significant impact on the thermal insulation of the facade system. It depends on many factors, including material properties, form and method of fixing for:

- facade elements console,

- anchors for fixing the console,

- anchors for fixing the thermal insulation layer.

There are innovative solutions for a ventilated building envelope, such as elevation, whose task is to heat or cool the building envelope, with air coming from a ground heat exchanger [19]. This system could be used in climatic areas with a high temperature amplitude in the diurnal and annual periods. 


\section{Temperature parameters in the area of the console mounting the facade system}

To analyze the temperature conditions in the area of the console and anchor that fixes the console to the structural wall, the ventilated facade shown in Fig. 1 was adopted. The material properties of the elements are shown in Table 1. The calculations were made for the cases of using two types of fastening anchor (of plain steel and stainless steel), two ways of isolating the console from the substrate, (with thermal pad and without pad) and two types of substrate to which the console can be fixed (wall made of silicate blocks and reinforced concrete wall) (Fig. 2). Five dimensions of the thermal pad were assumed:

- the original dimension equal to the dimension of the contact interface between the console and the substrate

- extension of the washer by $1,2,3$ and $4 \mathrm{~cm}$ to the variant of the original thermal pad.

In the analysis, particular care was taken to examine the temperature parameters at selected points, located on the connection of the thermal insulation with the wall and in the place where the console was mounted. The arrangement of selected points is shown in Fig. 3.

Table 1. Material data used in the calculation.

\begin{tabular}{|c|l|l|c|c|c|}
\hline \multirow{2}{*}{ No. } & \multirow{2}{*}{ Element } & Material & Density & $\begin{array}{c}\text { Heat transfer } \\
\text { coefficient }\end{array}$ & Heat capacity \\
\cline { 3 - 6 } & & $\rho, \mathrm{kg} / \mathrm{m}^{3}$ & $\lambda, \mathrm{W} /(\mathrm{m} \cdot \mathrm{K})$ & $\mathrm{c}_{\mathrm{w}}, \mathrm{J} /(\mathrm{kg} \cdot \mathrm{K})$ \\
\hline \multirow{2}{*}{1.} & \multirow{2}{*}{ Structural wall 24cm } & Silicate block & 1800 & 0.81 & 880 \\
\cline { 3 - 6 } & Reinforced concrete & 2500 & 1.70 & 840 \\
\hline \multirow{2}{*}{2.} & $\begin{array}{l}\text { Thermal isolation } \\
\text { 15cm }\end{array}$ & Mineral wool & 90 & 0.034 & 750 \\
\hline 3. & Facade panel & Lignocement plate & 1650 & 0.60 & 1500 \\
\hline 4. & Ventilated air layer & Air & 1.23 & 0.025 & 1008 \\
\hline \multirow{2}{*}{5.} & $\begin{array}{l}\text { Mounting console } \\
\text { (panel - wall) }\end{array}$ & Anodized aluminum & 2720 & 200.00 & 920 \\
\hline \multirow{2}{*}{6.} & $\begin{array}{l}\text { Anchors }(\text { console - } \\
\text { wall) }\end{array}$ & Plain carbon steel & 7800 & 50.00 & 450 \\
\cline { 2 - 6 } & Stainless steel & 7900 & 17.00 & 460 \\
\hline 7. & Thermal pad & PVC & 1390 & 0.17 & 900 \\
\hline 9. & Angle bar 50x50x2 & Aluminum & 2720 & 200.00 & 920 \\
\hline
\end{tabular}

The numerical calculations were performed using the ADINA Thermal module, which is intended to solve heat exchange problems in solids and structures [20]. The model of the external wall with a ventilated facade has been divided into structural parts corresponding to individual elements in the construction of the external partition. Structural parts have been defined as two-dimensional heat-conducting fields for which the corresponding material properties have been determined (Table 1). For the adopted material model, thermal conductivity and heat capacity are independent of temperature and time - constant material properties. For each group of materials a 4-node mesh of finite elements was generated, which in total gave over 200,000 nodes. In numerical calculations the initial temperature of the model equals $20^{\circ} \mathrm{C}$, constant value of external temperature $\theta_{\mathrm{e}}=-5^{\circ} \mathrm{C}$ and constant value of internal temperature $\theta_{\mathrm{i}}=20^{\circ} \mathrm{C}$ were accepted. According to [5], the heat transfer resistance values $\mathrm{R}_{\mathrm{si}}=0.13\left(\mathrm{~m}^{2} \cdot \mathrm{K}\right) / \mathrm{W}$ and $\mathrm{R}_{\mathrm{se}}=0.25\left(\mathrm{~m}^{2} \cdot \mathrm{K}\right) / \mathrm{W}$ were assumed respectively on the inside and outside edges of the model. Due to the type of building envelope, the heat transfer resistance $\mathrm{R}_{\mathrm{si}}=0.13\left(\mathrm{~m}^{2} \cdot \mathrm{K}\right) / \mathrm{W}$ was also adopted on the external 
side of the thermal insulation layer. Simulation of the heat flow was performed for 72 hour computational steps. The calculations were made for eight models according to Table 2.

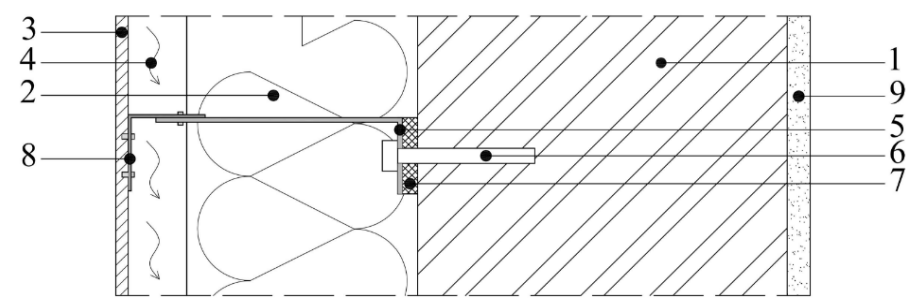

Fig. 2. Horizontal cross-section through a wall with a ventilated facade. Numbering of elements according to Table 1.

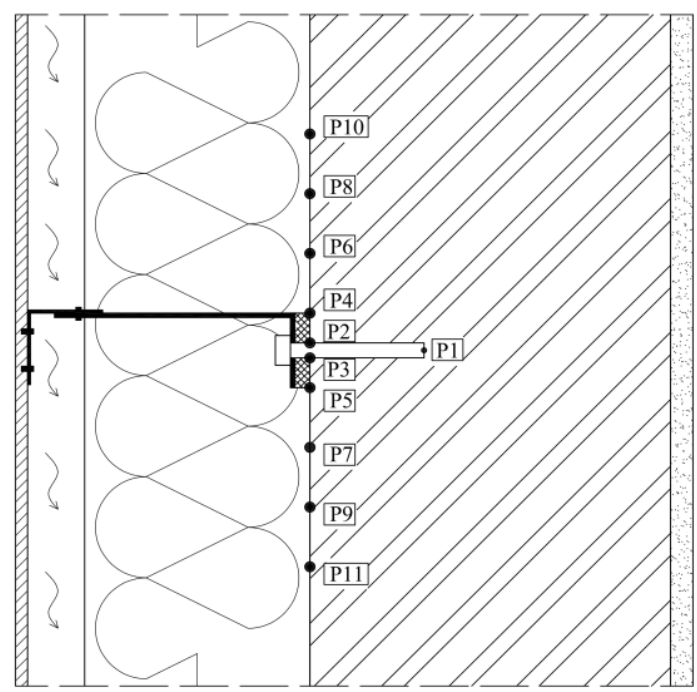

Fig. 3. Check points where temperature conditions were analysed.

For heat transfer in a body, it was assumed that the materials of the structure obey Fourier's law of heat conduction:

$$
q_{x}=-k_{x} \frac{\partial \theta}{\partial x} \quad q_{y}=-k_{y} \frac{\partial \theta}{\partial y} \quad q_{z}=-k_{z} \frac{\partial \theta}{\partial z}
$$

where:

$\mathrm{q}_{\mathrm{x}}, \mathrm{q}_{\mathrm{y}}, \mathrm{q}_{\mathrm{z}}$ - heat fluxes in the principal axis directions $\left[\mathrm{W} / \mathrm{m}^{2}\right]$

$\theta$ - temperature $\left[{ }^{\circ} \mathrm{C}\right]$

$\mathrm{k}_{\mathrm{x}}, \mathrm{k}_{\mathrm{y}}, \mathrm{k}_{\mathrm{z}}$ - proportionality factor (heat transfer coefficient) $[\mathrm{W} /(\mathrm{m} \cdot \mathrm{K})]$

The detailed calculation method is given in [20].

The obtained two-dimensional temperature distribution fields show the effect of an existing point thermal bridge. This phenomenon causes a clear area of lowering the temperature at the anchor point in the structural layer and increasing the temperature in the area of the mounting console passing through the mineral wool layer and the air layer (Fig. 4). Figure 4 shows the temperature distribution for the model where the console was mounted to the reinforced concrete wall, without a thermal pad. The slightly more favorable temperature conditions can be seen in the model with a stainless steel anchor. 
Table 2. Designation and description of calculation models.

\begin{tabular}{|c|c|c|c|}
\hline Designation & Structural wall & Anchor & Thermal pad \\
\hline 1.1 & silicate block & stainless steel & yes \\
\hline 1.2 & silicate block & plain steel & yes \\
\hline 2.1 & reinforced concrete & stainless steel & yes \\
\hline 2.2 & reinforced concrete & plain steel & yes \\
\hline 3.1 & silicate block & stainless steel & no \\
\hline 3.2 & silicate block & plain steel & no \\
\hline 4.1 & reinforced concrete & stainless steel & no \\
\hline 4.2 & reinforced concrete & plain steel & no \\
\hline
\end{tabular}
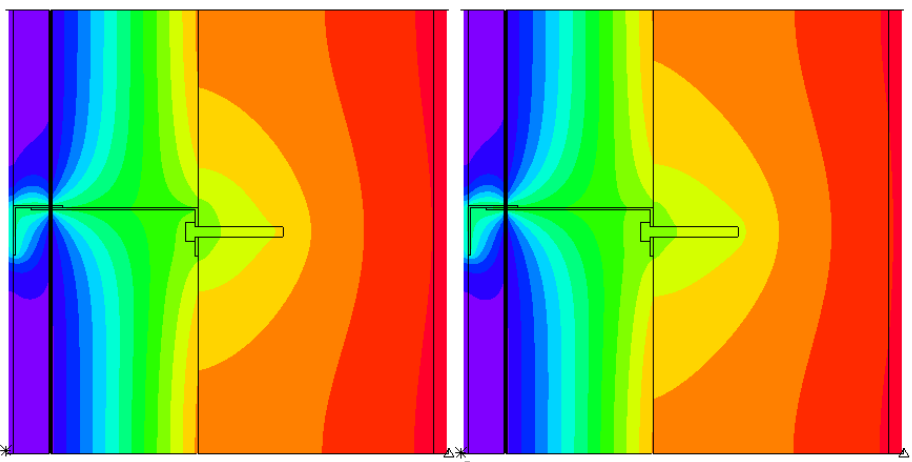

TEMPERAURE $\left[{ }^{\circ} \mathrm{C}\right]$ TIME [259200 s]

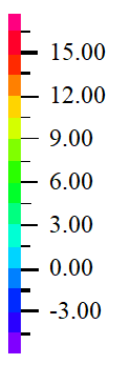

Fig. 4. Temperature distribution in the area of the console and fastening anchor, reinforced concrete wall, without an insulating pad, mounting anchor made of steel: a) stainless, b) plain steel

The use of a thermal pad under the console causes a visible change in the temperature distribution for the same console and structural wall (Fig. 5).
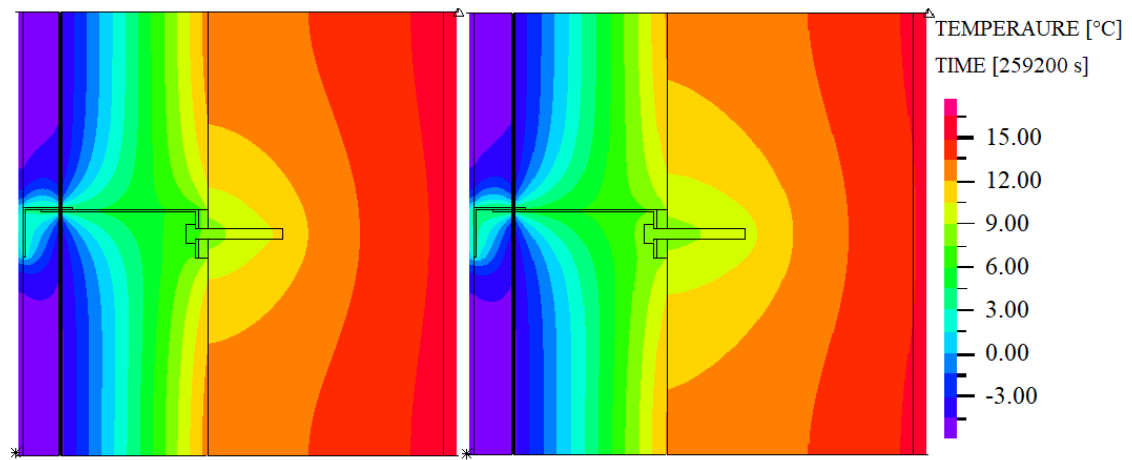

Fig. 5. Temperature distribution in the area of the console and fastening anchor, reinforced concrete wall, with insulating pad, mounting anchor made of steel: a) stainless, b) plain steel

However, the cooling zone of the structure can still be observed at the anchor point. A similar situation is for a wall made of silicate blocks and a thermal pad (Fig. 6).

The use of a wider thermal pad and lengthening it beyond the surface of the mounting console causes:

- significant temperature increase in the area of anchoring,

- more regular temperature distribution in the thermal insulation layer

- significant temperature increase on the console surface, over the entire thickness of the thermal insulation layer and in the air layer (Fig. 7). 

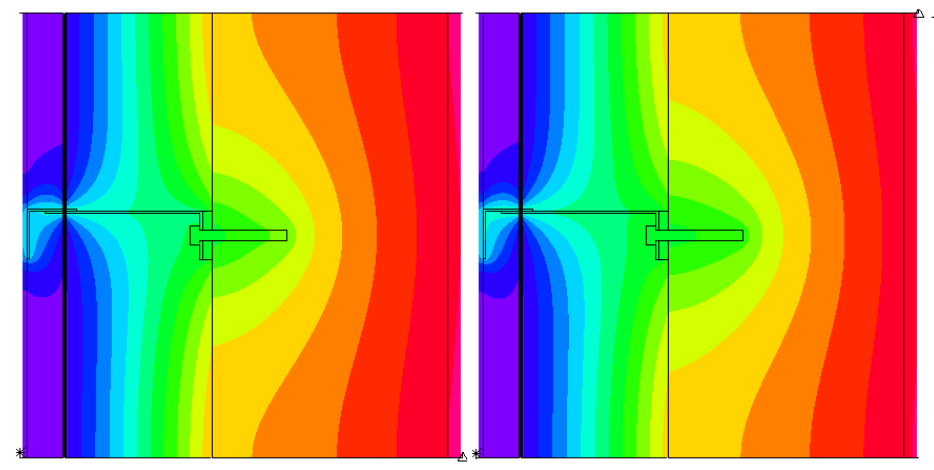

TEMPERAURE $\left[{ }^{\circ} \mathrm{C}\right]$

TIME [259200 s]

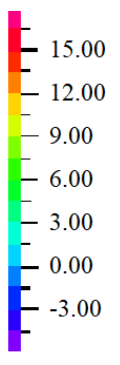

Fig. 6. Temperature distribution in the area of the console and fastening anchor, silicate block wall, with insulating pad, mounting anchor made of steel: a) stainless, b) plain steel
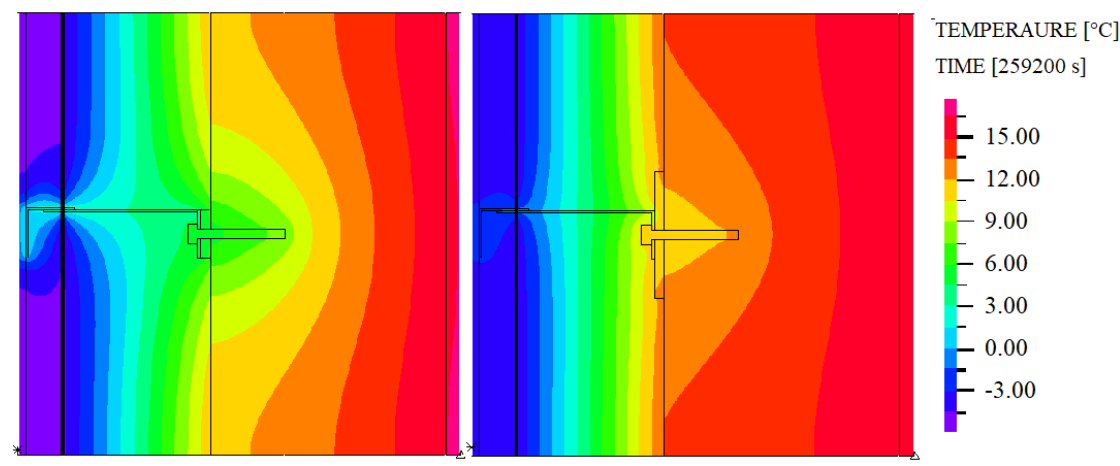

Fig. 7. Temperature distribution in the area of the console and fastening anchor, silicate block wall, with insulating pad, mounting anchor made of steel stainless, a) pad only under the console, b) pad extended $4 \mathrm{~cm}$ outside the console

Comparison the temperature distributions in Figures 5 and 6 , can be noticed a large differences between the results for the reinforced concrete wall and the silicate block walls. For a reinforced concrete wall, higher temperature values (approx. $3^{\circ} \mathrm{C}$ ) were obtained at the end of the aluminum console, where it passes from the layer of mineral wool to the air gap. This indicates a more intense heat flow and the effect of a point thermal bridge, than for a model with a wall made of silicate blocks.

In each of the analyzed models, the temperature distribution in the building envelopes with the plain steel anchor was less favorable. For this type of anchor, the disturbance zone of the temperature field is wider than with the stainless steel anchor.

Figures 4 and 5 present the temperature distributions obtained for the same material models, with the difference that for the models in Figure 5, a thermal pad for the console was used. The thermal pad changes the temperature distribution, especially in the area of its attachment. It reduces the area of disturbances in the course of isotherms and it is particularly well visible for a reinforced concrete wall and with stainless steel anchors (Fig. 5 a). For the models in Figure 7, the temperature values at the control points were compared according to (Fig 3).

The graphs in Fig. 8 show the linear temperature distribution at the boundary between the insulating layer and the structural wall and at the point of contact between the thermal pad and the mounting anchor with the structural wall. Using the wider pad the biggest change causes in the immediate position next to the anchor (points 2 and 4 ) - over $6^{\circ} \mathrm{C}$ difference between the models. 


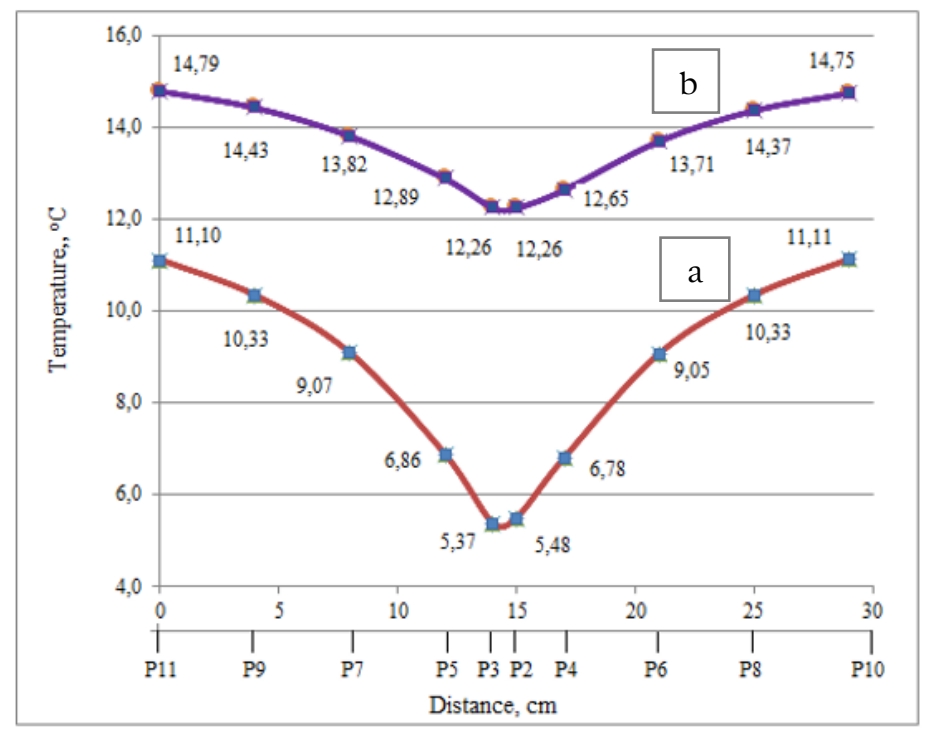

Fig. 8. Temperature values on the connection of the structural layer with the thermal insulation layer, a) pad only under the console, b) pad extended $4 \mathrm{~cm}$ outside the console

The greater the distance from the anchor, the smaller the difference is between the respective points (points 10 and 11 ), about $3.6^{\circ} \mathrm{C}$. The increase of temperature in the console mounting area also reduces the risk of condensation of water vapor and deterioration of insulating properties in the considered area.

\section{Summary}

Ventilated facade systems are more and more commonly used due to architectural values and many constructional advantages. In the case of such systems, it is necessary to take into account a number of adverse symptoms and processes that they are at risk of: displacement of elements from various types of loads, problem of vibration and noise, effect of thermal and acoustic bridges, moisture. One of the disadvantages of these systems is the formation of the point thermal bridge effect, in the place where the mounting consoles are located, which connect the structural wall with the facade. In this place, additional thermal bridges are created from fixing the thermal insulation layer to the structural layer. This problem becomes particularly important due to the increasing technical requirements in the field of thermal insulation of building envelopes, planned for 2021. There is a lack of detailed guidelines for designers that will allow for a correct approach to the design of a ventilated facade. The design of such structures should be fully approached, taking into account the multiple impacts that this structure is subjected to. In particular, to apply these solutions to existing external walls.

The paper presents a part of the heat exchange studies in ventilated facade construction, which indicates significant differences in heat exchange and the effect of a point thermal bridge, depending on the material and structural solution applied to the anchor, console and substrate. The point thermal bridge should be considered taking into account at the same time the console passing through the thermal insulation layer and the anchors in the construction layer. It was observed that more and more designers and technologists are looking for different solutions in order to minimize the effect of the point thermal bridge.

The use of a thermal pad at the connection point of the console with the structural layer and the anchor is one of the solutions to minimize the effect of the thermal bridge. In 
addition, the thermal pad is a form of acoustic insulation and shields against transferring vibrations from the ventilated facade system to the structural wall.

The extension of the thermal pad by a few centimeters, radically improves the temperature conditions and thus also the humidity conditions in the place of mounting the ventilated facade system to the wall construction. It also causes a more regular temperature distribution, both in the construction layer and the thermal insulation layer, which improves the insulating properties of the building envelope and helps reduce the energy demand for heating or cooling rooms.

\section{References}

1. D. Bikasa, K. Tsikaloudakia, K.J. Kontoleona, C. Giarmaa, S. Tsokaa, D. Tsirigoti, Ventilated Facades: Requirements and Specifications Across Europe, P. E. S. 38 (2017)

2. ETAG 034-2 Guideline for European Technical Approval of Kits for External Wall CladdingS Part II: Cladding Kits Comprising Cladding Components, Associated Fixings, Subframe and Possible Insulation Layer, EOTA Brussel (2012)

3. K. Schabowicz, M. Szymków, Details of aluminium substructures in ventilated facades. I.9(2017)

4. S. Kulczewska, W. Jezierski, Analiza rozwiązań złożonych mostków termicznych pod względem udoskonalania ich parametrów cieplnych, Budow. i Arch. 15(3) (2016)

5. PN-EN ISO 6946:2017-10 Komponenty budowlane i elementy budynku -- Opór cieplny i współczynnik przenikania ciepła -- Metody obliczania

6. PN-EN ISO 10211:2017-09 Mostki cieplne w budownictwie -- Strumienie ciepła i temperatury powierzchni -- Obliczenia szczegółowe

7. A. Ujma, Izolacyjność cieplna ściany zewnętrznej z elewacją wentylowaną. I.11/12 (2016)

8. J. Šadauskienè, J. Ramanauskas, L. Šeduikytė, M. Daukys, A. Vasylius, Simplified Methodology for Evaluating the Impact of Point Thermal Bridges on the High-Energy Performance of a Passive House. Sustainability 7 (2015)

9. A. Byrdy, Point Thermal Bridges in Walls with External Stone Layer, T. T. C. E. 3-B (2014)

10. V.M. Tusnina, To the problem of bearing capacity and operational reliability of suspended ventilated facade, Procedia Engineering 153 (2016)

11. T. Theodosioua, K Tsikaloudakia., D. Bikas, Analysis of the Thermal Bridging Effect on Ventilated Facades. Procedia Environmental Sciences 38 (2017)

12. T. Theodosiou, K. Tsikaloudaki, S. Tsoka, P. Chastas, Thermal bridging problems on advanced cladding systems and smart building facades, J. of C. P. 214 (2019)

13. A. Levinskytè, R. Bliūdžius, R. Kapačiūnas, The Comparison of a Numerical and Empirical Calculation of Thermal Transmittance of Ventilated Facade with Different Heat-Conductive Connections, J. of S. A. and C. Eng. V. 2/No23 (2018)

14. V. M. S. Francés, E. J. S. Escriva, J. M. P. Ojer, E. Bannier, V. C, Soler, G. S. Moreno, Modeling of ventilated facades for energy building simulation software. E. and B., 65 (2013)

15. M. H. Hanafi, M. U. Umar, A. A. Razak, Z. Z. A. Rashid, N.Z. Noriman, O. S. Dahham, An Introduction to Thermal Bridge Assessment and Mould Risk at Dampness Surface for Heritage Building, IOP Conf. Series: M. S. and Eng. 454 (2018)

16. T. Colinart, M. Bendouma, P. Glouannec, Building renovation with prefabricated ventilated facade element: A case study, Energy \& Buildings 186 (2019)

17.Z. Fišarová, L. Kalousek, M, Frank, and Roman Brzoň, The influence of ventilated facade on sound insulation properties of envelope walls, MATEC W.of Conf. 93 (2017)

18. M. Major, K. Kuliński, I. Major, Thermal and Dynamic Numerical Analysis of a Prefabricated Wall Construction Composite Element Made of Concrete-polyurethane, P. E. 190 (2017)

19. L. Liua, Z. Yua, H. Zhang, Simulation study of an innovative ventilated facade utilizing indoor exhaust air, Energy Procedia 121 (2017)

20. ADINA - Finite Element Analysis Software v. 9.3 - ADINA R\&D. Inc, USA 